\title{
Manipulating marine stratocumulus cloud amount and albedo: a process-modelling study of aerosol-cloud-precipitation interactions in response to injection of cloud condensation nuclei
}

\author{
H. Wang ${ }^{1}$, P. J. $\operatorname{Rasch}^{1}$, and G. Feingold ${ }^{2}$ \\ ${ }^{1}$ Pacific Northwest National Laboratory, Atmospheric Sciences \& Global Change Division, Richland, WA, USA \\ ${ }^{2}$ NOAA Earth System Research Laboratory, Chemical Sciences Division, Boulder, CO, USA
}

Received: 12 December 2010 - Published in Atmos. Chem. Phys. Discuss.: 13 January 2011

Revised: 20 April 2011 - Accepted: 24 April 2011 - Published: 6 May 2011

\begin{abstract}
We use a cloud-system-resolving model to study marine-cloud brightening. We examine how injected aerosol particles that act as cloud condensation nuclei $(\mathrm{CCN})$ are transported within the marine boundary layer and how the additional particles in clouds impact cloud microphysical processes, and feedback on dynamics. Results show that the effectiveness of cloud brightening depends strongly on meteorological and background aerosol conditions. Cloud albedo enhancement is very effective in a weakly precipitating boundary layer and in $\mathrm{CCN}$-limited conditions preceded by heavy and/or persistent precipitation. The additional CCN help sustain cloud water by weakening the precipitation substantially in the former case and preventing the boundary layer from collapse in the latter. For a given amount of injected $\mathrm{CCN}$, the injection method (i.e., number and distribution of sprayers) is critical to the spatial distribution of these $\mathrm{CCN}$. Both the areal coverage and the number concentration of injected particles are key players but neither one always emerges as more important than the other. The same amount of injected material is much less effective in either strongly precipitating clouds or polluted clouds, and it is ineffective in a relatively dry boundary layer that supports clouds of low liquid water path. In the polluted case and "dry" case, the $\mathrm{CCN}$ injection increases drop number concentration but lowers supersaturation and liquid water path. As a result, the cloud experiences very weak albedo enhancement, regardless of the injection method.
\end{abstract}

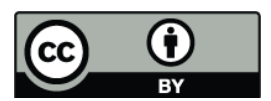

Correspondence to: $\mathrm{H}$. Wang

(hailong.wang@pnl.gov)

\section{Introduction}

Stratocumulus (Sc) clouds cover vast areas of the ocean surface. They significantly enhance the reflection of incoming solar radiation back to space but have little compensation from absorption/emission of longwave radiation, leading to a considerable net cooling of the Earth-atmosphere system. It has been argued that a $4 \%$ absolute increase in the cloud areal coverage (Randall et al., 1984) or a 0.06 increase in cloud albedo (Latham et al., 2008) of marine Sc can offset the warming by atmospheric $\mathrm{CO}_{2}$ doubling. Sc cloud albedo $\alpha_{\mathrm{c}}$ is a nonlinear function of cloud drop number concentration (hereafter, $N_{\mathrm{d}}$ ), drop size distribution and column-integrated liquid water content (i.e., liquid water path, LWP). The spatial extent and longevity of Sc clouds are partly determined by their precipitation efficiency. Acting as cloud condensation nuclei $(\mathrm{CCN})$, aerosol particles modify a sequence of cloud microphysical processes that also influence cloud dynamics. The combination of changes to cloud physics and dynamics determine $\alpha_{\mathrm{c}}$, spatial coverage and longevity of clouds. Thus, additional CCN in the marine boundary layer may alter the Earth's energy budget, with a subsequent impact on the temperature, and other aspects of its climate.

Based on this knowledge, the possibility of mitigating global warming by injecting aerosol particles into the marine boundary layer to brighten Sc clouds has been postulated by Latham (1990). Latham (2002) further proposed a technique for generating submicron sea-salt particles from the ocean surface with the goal of increasing $N_{\mathrm{d}}$ from nominal measured values of $50-200 \mathrm{~cm}^{-3}$ to about $400 \mathrm{~cm}^{-3}$. The method aims at producing a narrow $\mathrm{CCN}$ size distribution so that particles are readily activated to cloud droplets, but giant nuclei that may promote drizzle formation and significantly reduce $\alpha_{\mathrm{c}}$ (Feingold et al., 1999) are avoided.

Published by Copernicus Publications on behalf of the European Geosciences Union. 
More specifically when considering the practicalities of implementation, Salter et al. (2008) proposed using a fleet of wind-driven spray vessels to increase the number of sea-salt particles through injection at a rate of $1.12 \times 10^{17} \mathrm{~s}^{-1}$ over a $7.72 \times 10^{10} \mathrm{~m}^{2}$ ocean surface area, which gives an areaaverage particle injection rate of $1.45 \times 10^{6} \mathrm{~m}^{-2} \mathrm{~s}^{-1}$. Their back-of-the-envelope calculation with some general assumptions suggested that this injection rate is expected to increase marine Sc cloud mean $N_{\mathrm{d}}$ from 65 to $191 \mathrm{~cm}^{-3}$ daily, leading to an enhancement of 0.09 in $\alpha_{\mathrm{c}}$ solely based on the aerosol albedo effect (Twomey, 1977), i.e., assuming cloud LWP remains unchanged.

With a relatively simple computational assessment of the proposed technique, Bower et al. (2006) provided quantitative support for achieving the required $\alpha_{\mathrm{c}}$ enhancement to compensate the global warming resulting from doubling of pre-industrial $\mathrm{CO}_{2}$. More recently, the proposed cloud brightening idea has been evaluated by several global climate model studies (e.g., Latham et al., 2008; Jones et al., 2009; Rasch et al., 2009; Bala et al., 2010). They explored the impact of prescribed changes in cloud drop size and/or $N_{\mathrm{d}}$ on global temperature, precipitation and other components of the Earth's climate system. However, the changes were simply prescribed in the models; there was no attempt to assess whether it was plausible to inject aerosol in the boundary layer in order to change $N_{\mathrm{d}}$. In response to this limitation, Korhonen et al. (2010) examined the validity of the assumption of achieving $N_{\mathrm{d}}=375 \mathrm{~cm}^{-3}$ using a global aerosol model which explicitly simulated the transport of injected sea-salt particles and their effect on natural aerosol production processes. However, the model was not designed to represent aerosol effects on cloud and boundary layer dynamics, and used prescribed meteorological fields to produce the clouds. They found that the fractional changes in $N_{\mathrm{d}}$ varied substantially between the four Sc regions that were seeded with wind-driven seawater spray because of differences in wind-dependent injection rate and variations in base-state background aerosol. They also found that the diagnosed incloud maximum supersaturation was highly reduced by the influx of sea-salt particles, preventing existing background aerosols from being activated to cloud droplets. The suppression of supersaturation is consistent with a Lagrangian parcel model study of ship tracks by Russell et al. (1999).

The inability of global aerosol and climate models to adequately represent cloud-scale dynamics and microphysics raises questions about the validity of some model results that are contingent on the representation of aerosol-cloud interactions. As discussed also by Korhonen et al. (2010), the spreading of the seawater spray into clouds and the further detailed interactions with cloud microphysics are important in evaluating the effectiveness of the injection in enhancing $\alpha_{\mathrm{c}}$, but are not resolved in their model.

The global studies, parcel model calculations, and prescribed dynamical calculations mentioned above provide important insight into some aspects of aerosol effects on clouds and climate. But they do not allow for dynamical interactions and some important interactions between aerosol, clouds and the local meteorology. Drop collection and cloud scavenging can significantly reduce the total amount of CCN available for cloud formation (e.g., Albrecht, 1989; Ackerman et al., 1993; Wood, 2006; Wang et al., 2010) and changing the precipitation field can have important consequences for many aspects of the cloud circulations themselves (e.g., Wang and Feingold, 2009a, b; Feingold et al., 2010). Processes such as these need to be considered to gain a better understanding of required particle injection rates if one is to achieve the goal of cloud brightening, and to evaluate the broader-scale impact of geoengineering.

Large-eddy simulation or cloud resolving modelling has proven to be a useful tool for improving process-level understanding. In this study, we run cloud-system resolving model simulations using the Weather Research and Forecasting (WRF) model to investigate how the injected aerosol particles are transported in the marine boundary layer by organized eddies and how the additional $\mathrm{CCN}$ impact modelresolved cloud microphysical processes and feedback to dynamics. Previous sensitivity experiments to examine the response of precipitating open cellular Sc clouds and nonprecipitating closed-cell Sc decks to underlying ship emissions using the same modelling framework demonstrated the viability of this approach (Wang and Feingold, 2009b).

Unlike the simple calculations by Salter et al. (2008), where it was assumed that all sea-salt particles from surface sprayers can be dispersed through the depth of the boundary layer in about two hours, we simulate the surface injection in the form of single or multiple moving point-sources and perfect uniform area-source all of which have the same average injection rate (i.e., the same total amount of particles are injected into the entire model domain per unit time). The goal is to examine the sensitivity of cloud-aerosol interactions to the injection strategy, cloud morphology, and meteorological background. We explore the response of the model to an injection rate of $\left(1.45 \times 10^{6} \mathrm{CCN}\right.$ particles $\left.\mathrm{m}^{-2} \mathrm{~s}^{-1}\right)$ under different preexisting aerosol initial conditions and different background meteorological conditions. This injection rate was estimated by Salter et al. (2008) and Latham et al. (2008) as that needed to achieve an enhancement of marine Sc cloud albedo $\Delta \alpha_{\mathrm{c}}=0.062$ and produce a global average forcing of $-3.7 \mathrm{~W} \mathrm{~m}^{-2}$.

The present study extends the work of Wang and Feingold (2009b) by considering a number of different CCN injection strategies/rates, and examines diurnal variation of the impact of CCN injection since cloud brightening is only meaningful in the daytime.

We note that, while focusing on advertent cloud brightening, the study also has the salutary aspect of elucidating fundamental aerosol-cloud interaction processes in regions of aerosol gradients. This subject remains relatively unexplored and is therefore of broad interest. 


\section{Model and numerical experiments}

Cloud-system-resolving simulations are performed using the Advanced Research WRF model (version 3.1.1) with a coupled double-moment warm-rain microphysical scheme (Feingold et al., 1998; Wang et al., 2009; Wang and Feingold, 2009a). The microphysical scheme assumes lognormal basis functions to represent $\mathrm{CCN}$, cloud and rain drop size distributions, with prescribed geometric standard deviations of 1.5, 1.2 and 1.2, respectively. The cutoff diameter between the cloud and rain size distributions is $50 \mu \mathrm{m}$. For simplicity, cloud-active aerosol particles (or $\mathrm{CCN}$ ) are assumed to be composed of sea salt with a mean dry diameter of $0.2 \mu \mathrm{m}$ in the marine boundary layer. A single scalar is used to represent the CCN, including its sources (surface emission) and sinks (coalescence scavenging and wet removal). With this representation, sensitivity to the aerosol composition and size distribution are not considered, and therefore, a change in the $\mathrm{CCN}$ is reflected in the number concentration alone. Wang and Feingold (2009b) used the same model configuration for their ship-track studies.

Model simulations are summarized in Table 1. They are performed in a $60 \times 120 \times 1.5 \mathrm{~km}^{3}$ domain (with doubly periodic lateral boundary conditions) for $30 \mathrm{~h}$, with a grid spacing of $300 \mathrm{~m}$ in the horizontal and $\sim 30 \mathrm{~m}$ in the vertical. Two meteorological scenarios are investigated based on measurements from the first and second research flight (hereafter RF01 and RF02) of the Second Dynamics and Chemistry of Marine Stratocumulus (DYCOMS-II) field campaign. Details about the case descriptions and initial sounding profiles can be found in the eighth and ninth GEWEX Cloud System Study (GCSS) Boundary-layer Cloud stratocumulus case studies (e.g., Stevens et al., 2005; Ackerman et al., 2009). The RF01 case is warmer and drier than the RF02 case, particularly in the free-troposphere. Also, precipitation was observed in the RF02 case but not in the RF01 case. For this reason, in Table 1 and hereafter, the RF01 and RF02 cases are referred to as "dry" and "wet", respectively. In the initial sounding, total water mixing ratio decreases from 9.45 (9.0) $\mathrm{g} \mathrm{kg}^{-1}$ in the boundary layer to $5.0(1.5) \mathrm{g} \mathrm{kg}^{-1}$ in the free-troposphere in the RF02 (RF01) case. In response to the warmer and drier boundary-layer air, surface sensible and latent heat fluxes in RF01 differ from those in RF02 (15 vs. $16 \mathrm{~W} \mathrm{~m}^{-2} ; 115$ vs. $93 \mathrm{~W} \mathrm{~m}^{-2}$ ). An identical uniform largescale divergence rate $\left(3.75 \times 10^{-6} \mathrm{~s}^{-1}\right)$ is used for both cases as in the aforementioned modelling studies. Mean winds are removed from the initial soundings so that sprayer tracks are not significantly advected in the domain.

In the model simulations, the initial background $\mathrm{CCN}$ number concentration $N_{\mathrm{c}}$ is assumed to represent an average maritime environment $\left(100 \mathrm{mg}^{-1}\right)^{1}$, a cleaner $\left(50 \mathrm{mg}^{-1}\right)$ and a more polluted one $\left(200 \mathrm{mg}^{-1}\right)$, respectively. Wang et

\footnotetext{
${ }^{1}$ The model units are with respect to mass of air; $1 \mathrm{mg}^{-1}=1 \mathrm{~cm}^{-3}$ at an air density of $1 \mathrm{~kg} \mathrm{~m}^{-3}$.
}

Table 1. Summary of numerical experiments; dry (D) and wet (W) conditions refer to DYCOMS-II RF01 and RF02 sounding respectively; note that the units of $\mathrm{mg}^{-1}$ for $\mathrm{CCN}$ number concentration $N_{\mathrm{c}}$ are equivalent to $\mathrm{cm}^{-3}$ when the air density is $1 \mathrm{~kg} \mathrm{~m}^{-3}$. "One sprayer" sails along $x$-direction at the center of $y$-direction $(y=30 \mathrm{~km})$ at $5 \mathrm{~m} \mathrm{~s}^{-1}$, and "three sprayers" are $20-\mathrm{km}$ apart. "Uniform" means that particles are injected from the entire surface area uniformly.

\begin{tabular}{lrrl}
\hline Experiment & $\begin{array}{r}\text { Initial LWP } \\
\left(\mathrm{g} \mathrm{m}^{-2}\right)\end{array}$ & $\begin{array}{r}\text { Initial } \\
N_{\mathrm{c}}\end{array}$ & $\begin{array}{l}\text { Injection } \\
\text { method }\end{array}$ \\
\hline W100 & 170 & 100 & - \\
W100-P1 & & & 1 sprayer \\
W100-P3 & & & 3 sprayers \\
W100-U & & & uniform \\
W50 & & 50 & - \\
W50-P1 & & & 1 sprayer \\
W50-P3 & & & 3 sprayers \\
W50-U & & & uniform \\
W200 & & 200 & - \\
W200-P1 & & & 1 sprayer \\
W200-P3 & & & 3 sprayers \\
W200-U & & & uniform \\
D100 & 60 & 100 & - \\
D100-P1 & & & 1 sprayer \\
D100-P3 & & & 3 sprayers \\
D100-U & & & uniform \\
\hline
\end{tabular}

al. (2010) showed that without a source to replenish aerosol, depletion by cloud scavenging and drop coalescence can cause the collapse of marine boundary layer within a few hours (Ackerman et al., 1993). For simplicity, a steady source rate of $2 \mathrm{mg}^{-1} \mathrm{~h}^{-1}$ is assumed here to account for the loss of CCN particles due to coalescence of cloud drops and wet removal. With a detailed aerosol nucleation mechanism, Korhonen et al. (2010) did not find significant suppression of new particle formation by seawater spray. It is thus reasonable to assume a constant natural source of $\mathrm{CCN}$ (i.e., sea-salt emission and growth of newly formed particles) in both our control and sensitivity simulations.

In the sensitivity experiments where $\mathrm{CCN}$ are injected into the marine boundary layer from the surface, the same emission rate of $1.45 \times 10^{6} \mathrm{~m}^{-2} \mathrm{~s}^{-1}$ suggested by Salter et al. (2008) is used, which is equivalent to increasing CCN number concentration in the first model layer by about $375 \mathrm{~cm}^{-3}$ per hour for the uniform injection case. The point sources, moving at $5 \mathrm{~m} \mathrm{~s}^{-1}$, start from the left edge of the model domain and repeat the journey about four times during the 30-h simulations. The multi-sprayer case divides the particle source into three point sources spaced $20 \mathrm{~km}$ apart (north-south). For the point-sprayer cases (i.e., single and multiple sprayers) injected particles are initially much more concentrated in a single grid box upon injection, closely 
mimicking the proposed wind-driven spray-vessel technique of Salter et al. (2008). They assumed a single sprayer could seed a target region of $7.72 \times 10^{10} \mathrm{~m}^{2}$, an area about 10 times the size of our model domain, and assumed an injection rate (\# of particles per second) from a sprayer that is about 10 times larger than we use in our single-sprayer cases.

For simplicity in calculating $\mathrm{CCN}$ activation (i.e., clouddroplet nucleation) based on model predicted supersaturation and critical dry radius, the injected particles are assumed to follow the same lognormal distribution used to represent the background $\mathrm{CCN}$ population, so the idea of injecting monodisperse sea salt particles (Latham et al., 2008) is not specifically pursued in this study. The process of producing sea salt particles from seawater and its impact on environmental conditions (i.e., evaporative cooling and moistening) are not considered. We also use passive tracers (i.e., particles injected in the same way as CCN but not involved in microphysical processes) to characterize the dispersion process and to show how injected particles are spatially distributed in the experiments that use three different injection methods.

\section{Results and discussion}

The meteorological configuration generates an initial LWP of $170 \mathrm{~g} \mathrm{~m}^{-2}$ in RF02 ("wet" or W simulations; Table 1) and $60 \mathrm{~g} \mathrm{~m}^{-2}$ in RF01 ("dry" or D simulations; Table 1). In an environment with the same background $N_{\mathrm{c}}=100 \mathrm{mg}^{-1}$, clouds in the W100 series have a greater potential than the D100 series to precipitate. For W simulations, a decrease in $N_{\mathrm{d}}$ enhances precipitation (e.g., the W50 series), whereas the increase in $N_{\mathrm{d}}$ in the W200 series suppresses precipitation. The various W100 and W50 experiments are designed to demonstrate how the different $\mathrm{CCN}$ injection methods affect $\alpha_{\mathrm{c}}$ in stratocumulus that produce varying amounts of precipitation and associated dynamical feedbacks. This is contrasted with the W200 and D100 simulations that produce non-precipitating Sc where we explore how much the injection enhances $\alpha_{\mathrm{c}}$ via the aerosol albedo effect and associated feedbacks in a relatively wet and dry environment, respectively.

\subsection{Distribution of injected particles in the boundary layer}

In global modelling studies, it is generally assumed that aerosol particles mix rapidly within the grid box, and that the clouds can be described by a probability distribution function (PDF). It is often assumed that only one cloud type is present in a grid box on the order of $10^{4} \mathrm{~km}^{2}$. Salter et al. (2008) used the same assumption in their simple calculation of $N_{\mathrm{d}}$ enhancement by injection. Our highresolution modelling results show that this is a poor assumption when spatially heterogeneous sources of $\mathrm{CCN}$ are introduced within a region the size of a typical large-scale model grid box. Wang and Feingold (2009b) showed that gradients in CCN (and therefore precipitation) generate mesoscale circulations that exhibit strong heterogeneity in the cloud field; for example, open-cellular cloud fields tend to form at relatively low aerosol concentrations that favor drizzle. In turn, these mesoscale circulations affect the dispersal of ship exhaust particles. The dispersal of particles in precipitating open cells is very efficient, so that by influencing rain production, the ship-emitted particles can modify open-cell circulations and thereby feedback on the dispersion process.

Passive tracers are used to characterize the dispersion process for the three different injection methods. Shaded colours in Fig. $1 \mathrm{~b}$ and $\mathrm{c}$ illustrate the horizontal and vertical distribution of the passive tracer particles at $t=8 \mathrm{~h}$ in the W50 cases. The injected particles are lofted into clouds by updraughts within minutes, as shown by the vertically well-mixed features at any given location. However, the horizontal distribution of these particles injected from point-sources is far from uniform. Particles introduced from a point source mix horizontally through transport by local eddies, and the mixing timescale is relatively large over spatial scales of tens of $\mathrm{km}$. This produces along-track and transverse gradients in $\mathrm{CCN}$ number concentration, which can generate dynamical feedbacks from rain processes that impact clouds well beyond the traditional "aerosol indirect effects" (Wang and Feingold, 2009b). For instance, in Fig. 1a we see generally enhanced $\alpha_{\mathrm{c}}$ along the injection plumes but decreased $\alpha_{\mathrm{c}}$ on either side, and we also see differences in cloud structure near $x=0$ and $120 \mathrm{~km}$ boundaries (W50-P1 and W50-P3) where large gradients in $\mathrm{CCN}$ number concentration exist. Moreover, as discussed in Wang and Feingold (2009b), dynamical feedbacks associated with plumes in close proximity can interact and thereby further modify clouds. For example, in Fig. 1a (W50-P3 case; between $x=0$ and $50 \mathrm{~km}$ in the middle panel), $\alpha_{\mathrm{c}}$ is enhanced in between plumes instead of along the plumes. The complex, unpredictable effects through changing dynamics are likely significant only in precipitating marine stratocumulus. Nonetheless, for the injected $\mathrm{CCN}$ to be able to affect clouds through the albedo effect they have to be present in clouds. How long does it take for a significant amount of injected CCN to spread transversely over clouds in the entire domain? To address this, we look at the time evolution of particle dispersion. Black contours in Fig. 2 show the $y$-time distribution of number concentration of passive tracers (average value within the clouds) in the W50 series (i.e., precipitating cases) and the W200 series (i.e., non-precipitating cases). The injection methods are critical to the temporal and spatial distribution of particles in clouds. The uniform injection method increases incloud CCN steadily over the entire domain for both cases (Fig. 2e and f), for example, by $10 \mathrm{mg}^{-1}$ within two hours. With one or three sprayers, the injected particles do not mix quickly normal to the ship track. It takes over $15 \mathrm{~h}$ for the domain-wide in-cloud CCN concentration to be enhanced by $10 \mathrm{mg}^{-1}$ if released by just one sprayer. As a result, the 


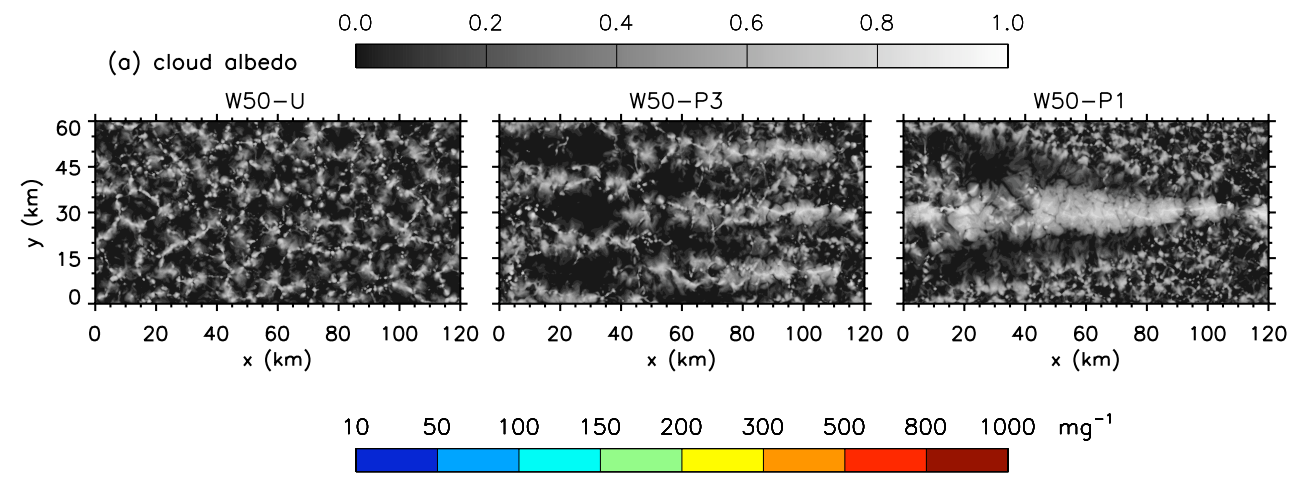

(b) horizontal distribution of particles
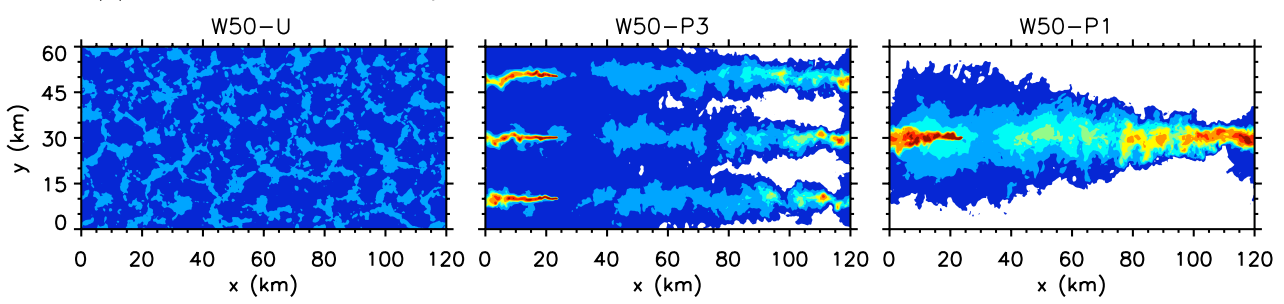

(c) vertical distribution of particles
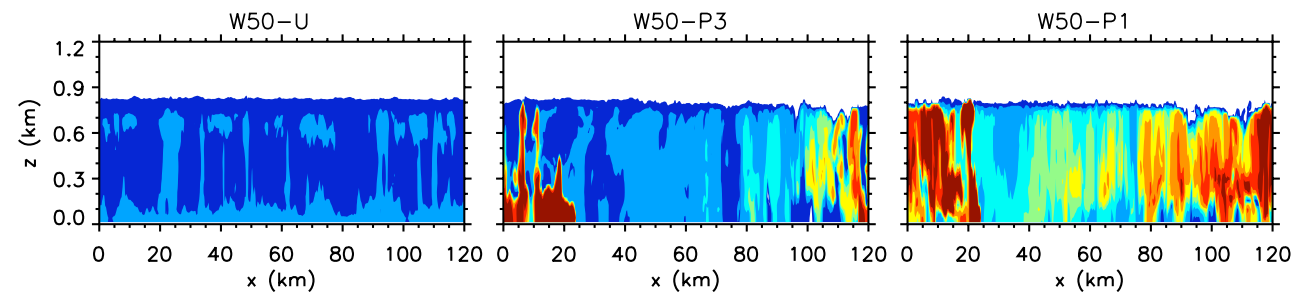

Fig. 1. Snapshot of (a) cloud albedo, (b) boundary-layer mean number concentration of injected particles on the $x$ - $y$ plane, and (c) particle number concentration on a $x-z$ cross section at $y=30 \mathrm{~km}$ (track of the central sprayer) at $t=8 \mathrm{~h}$ when sprayers are at $x=24 \mathrm{~km}$ on their second journey. Particles in the plots are passive tracers providing a measure of the maximum extent of mixing resulting from the particle source.

spatial inhomogeneity (e.g., maxima along sprayer paths and minima in between paths) remains strong in the point-sprayer cases. The impact on cloud optical properties is discussed in Sect. 3.3.

If we use the in-cloud tracer number concentration reaching e.g., $100 \mathrm{mg}^{-1}$ to indicate the efficiency of transport and dispersion, then overall, it is more efficient in the precipitating cases, in which updraughts are narrow yet very strong and particles are lofted into clouds quickly before being well mixed below clouds. On the other hand, cumuliform cloud walls in the W50 cases have a lower cloud base, which means that particles injected from the surface are able to enter clouds faster than in the W200 cases. This also causes the locally more concentrated $\mathrm{CCN}$ perturbations along the sprayer paths.

Shaded colours in Fig. 2 show total particle number concentration $\left(N_{\mathrm{t}}\right)$ within the clouds in the W50 and W200 series. Overall, the enhancement of total particles by injection (compared to the control runs) should be smaller than the passive tracer concentrations due to drop coalescence and/or rainout; however, they are quite well correlated in all cases. Using the passive tracer concentration as a proxy for maximum drop number enhancement suggests that the proposed injection rate by Salter et al. (2008) will not be strong enough to increase $N_{\mathrm{d}}$ by $200 \mathrm{~cm}^{-3}$ (the value desired by Latham et al., 2002) within one day. Nonetheless, as will be discussed later, the desired increment in $N_{\mathrm{d}}$ is not necessary to achieve the desired enhancement in $\alpha_{\mathrm{c}}$ for some of the cases considered here.

\subsection{Impact of aerosol injection on supersaturation and cloud droplet activation}

Supersaturation is a key parameter in cloud microphysics. Not only does it determine activation and diffusional growth of cloud droplets, but it also acts to buffer aerosol effects on cloud (Stevens and Feingold, 2009), i.e., for a given updraught velocity an increase in $N_{\mathrm{d}}$ lowers supersaturation, and thus slows down further activation of new droplets. Supersaturation can therefore be viewed as a field that 


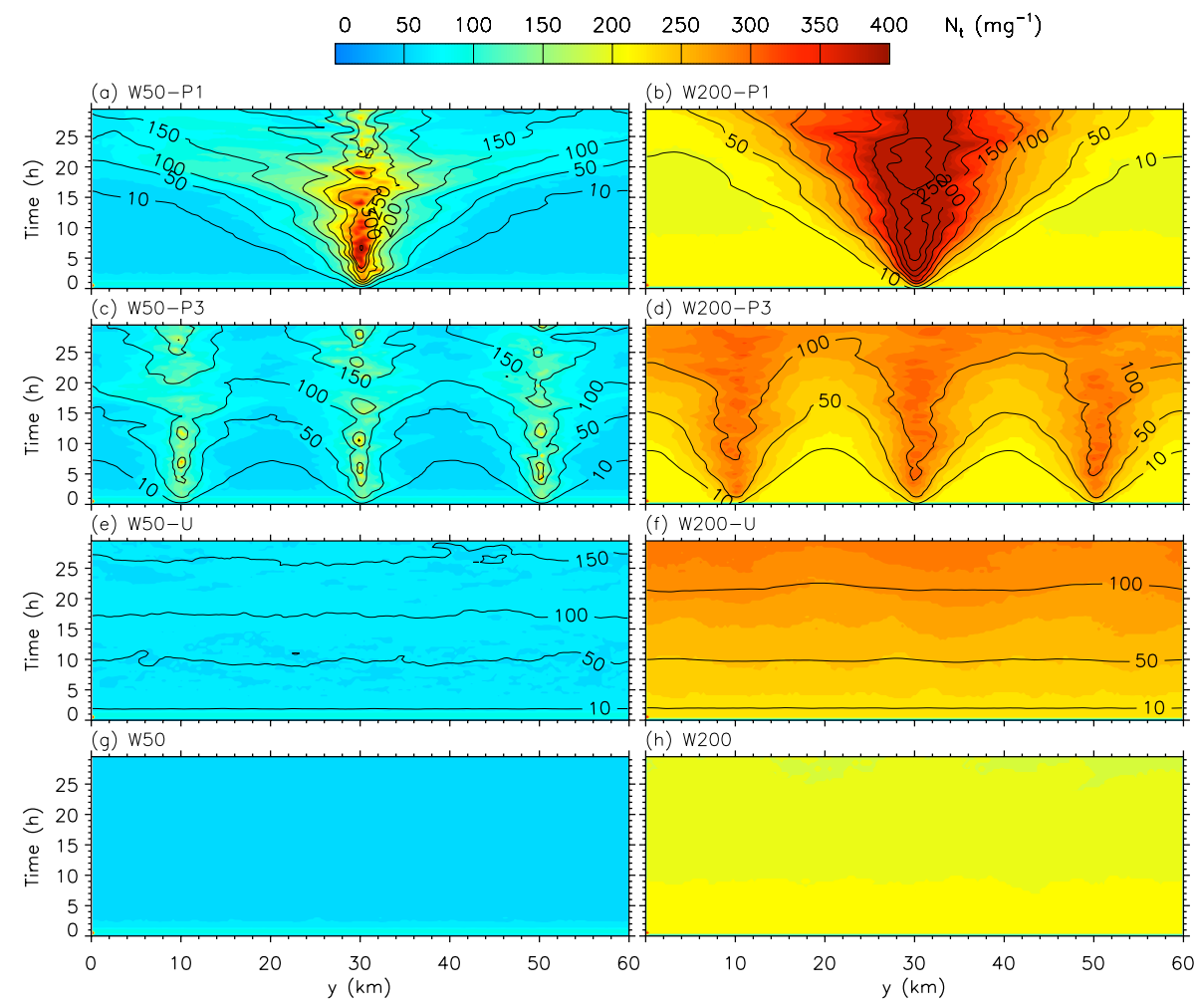

Fig. 2. $y$-time space distribution of in-cloud passive tracer number concentration (black contours: $10,50,100,150,200,300 \mathrm{mg}^{-1}$ ) and in-cloud total particle number concentration $N_{\mathrm{t}}$ (cloud drop concentration $N_{\mathrm{d}}$ plus interstitial CCN concentration $N_{\mathrm{c}}$; in colours) in the W50 series (left) and the W200 series (right). Quantities are averaged along the x-direction.

self-regulates with respect to sources (primarily updraughtdriven) and sinks (condensation). Figures 3 and 4 show the $y$-time distribution (averaged along the $x$-dimension) of incloud maximum supersaturation $s_{\max }$ and number concentration of unactivated $\mathrm{CCN}$ for the four sets of simulations. Although there are spatial, temporal and case-by-case complexities in the change of $s_{\max }$, the injection of aerosol causes a net decrease in the overall domain-average $s_{\max }$ in all cases, compared to the corresponding control simulations. In the non-precipitating cases, reduction in $s_{\max }$ along the injection plumes is quite evident. However, it is more complicated in the precipitating cases. The precipitating cases have overall higher $s_{\max }$ than the non-precipitating cases, including the polluted (W200 series) and dry cases (D100 series). First there is the expected increase in $s_{\max }$ in response to a smaller condensation sink when drop size is large. However there is a different, less direct change in $s_{\max }$ due to dynamical responses. Evaporation of rain drops in the subcloud layer drives downdrafts which diverge upon reaching the surface and collide with adjacent outflows. These become regions of strong convergence that channel moisture into clouds in strong updraughts (Wang and Feingold, 2009a, b) and therefore also contribute to an increase in $s_{\max }$. During the nighttime when clouds thicken and the chance of precipitation increases, the contribution from this precipitation-driven dynamical feedback is important. During the daytime, $s_{\max }$ is smaller both because boundary layer turbulence is in general weaker, and because the weaker precipitation provides less opportunity for colliding outflows and stronger convection. For instance, precipitation is shut off by the uniform CCN injection in W100-U; as a result, $s_{\max }$ is substantially reduced when compared to the control case W100, approaching that in the W200 case.

The two influences on $s_{\max }$ in a plume can work in tandem, or counter one another. Along the injection plumes they can work in tandem, reducing $s_{\max }$ by activating more $\mathrm{CCN}$ but also by suppressing rain. On the other hand, adjacent to the plume precipitation can drive a convergent flow that pumps moisture into the plume (Wang and Feingold, 2009b) and thereby increase $s_{\max }$ along the injection plumes, countering the local suppression. Sometimes, the latter is stronger so that $s_{\max }$ experiences a net increase in the plumes (e.g., Fig. 3a after $t=20 \mathrm{~h}$ ). Relatively weak precipitation during the day (between $t=6$ and $18 \mathrm{~h}$ ) causes a net reduction of $s_{\max }$ along the plumes in most precipitating cases.

The concentration of unactivated $\mathrm{CCN}$ along the plumes is largely determined by $s_{\max }$. In the W200 and D100 cases, the reduction in $s_{\max }$ correlates quite well with the number concentration of unactivated CCN in clouds. However, it is more complicated in the precipitating cases owing to the 


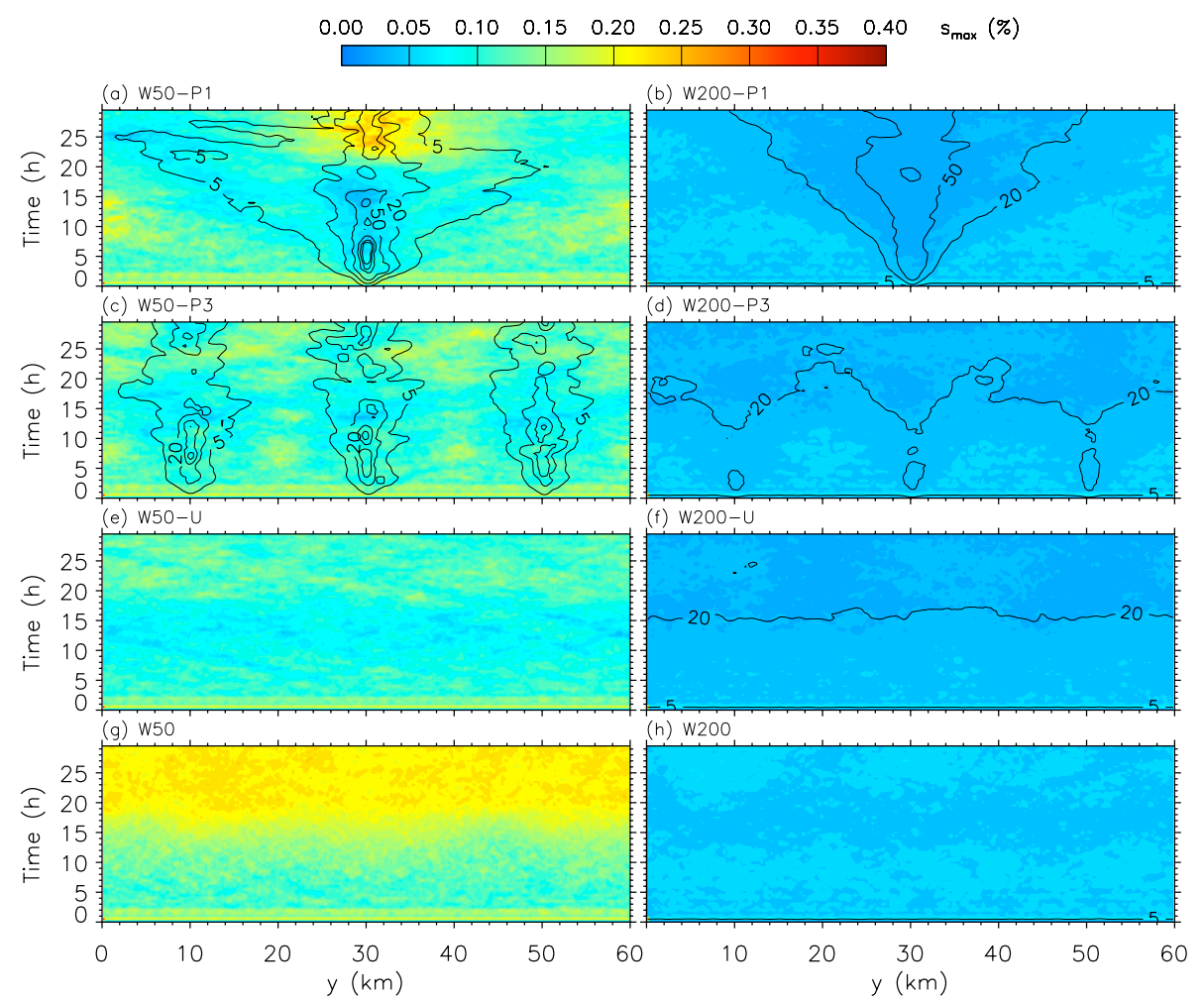

Fig. 3. Same as Fig. 2 but for in-cloud unactivated CCN number concentrations $N_{\mathrm{c}}$ (black contours: $5,20,50,100,150,200 \mathrm{mg}{ }^{-1}$ ) and maximum supersaturation (colours).

aforementioned precipitation-driven mesoscale circulations that transport moisture and $\mathrm{CCN}$ together. For example, at some places along the plumes, both $s_{\max }$ and the concentration of unactivated $\mathrm{CCN}$ are relatively high. It is puzzling that there are more unactivated in-cloud $\mathrm{CCN}$ at some places in the clean cases (e.g., W50-P1, W50-P3 and W100P1) than in the polluted cases (e.g., W200-P1 and W200P3). This is because a large number of particles are carried in undiluted air parcels and lofted into precipitating clouds that have much lower cloud bases. Supersaturation is just not high enough to activate them all, especially, in weakly convective regions.

\subsection{Sprayer- and regime-dependent enhancement in cloud albedo}

It has been shown that the spatial distribution of injected sea-salt particles and its impact on $N_{\mathrm{d}}$ depends strongly on the distribution of sprayers. How does that affect the effectiveness of overall cloud brightening under different initial aerosol and meteorological conditions? Table 2 summarizes time- and domain-averaged cloud properties calculated for all experiments and changes in cloud albedo $\left(\Delta \alpha_{\mathrm{c}}\right)$ due to $\mathrm{CCN}$ injections relative to the corresponding baseline simulation. Mean cloud fraction is also included in the table to facilitate interpretation of cloud-average quantities.
Assuming that the initial boundary-layer meteorology and background aerosol are independent of one another, boosting CCN number concentration from $<100 \mathrm{mg}^{-1}$ to $200 \mathrm{mg}^{-1}$ can enhance $\alpha_{\mathrm{c}}$ dramatically ( 0.6 in W200 vs. 0.17 in W100 and 0.15 in W50). For individual groups with different initial conditions, the cloud brightening is most effective in the W100 configuration and W50 ranks next. Both are precipitating cases with a relatively low $\alpha_{\mathrm{c}}$ in the baseline simulation $(<0.2)$. Suppressing rain to retain cloud water turns out to be an effective way of increasing cloud fractional coverage and enhancing $\alpha_{c}$. An ideal cloud brightening scenario would be one where closed-cell stratocumulus are prevented from opening up by suppressing precipitation; this requires a persistent high aerosol environment.

The time evolution of some key cloud properties in the W100 and W50 series is shown in Figs. 5 and 6 to illustrate how particles injected via different methods influence the evolution of precipitation and, in turn, its feedback on the efficacy of the injections. In the baseline simulations (green lines), the cloud deck breaks up immediately after precipitation starts, as indicated by the simultaneous decrease of cloud fraction. LWP and $N_{\mathrm{d}}$ decrease too as a result of precipitation. This, together with the daytime solar heating, reduces domain-average $\alpha_{\mathrm{c}}$ from about 0.6 to below 0.2. Not only is the precipitation weaker in the W100 case but it also starts later than in the W50 case, which makes the enhancement of 


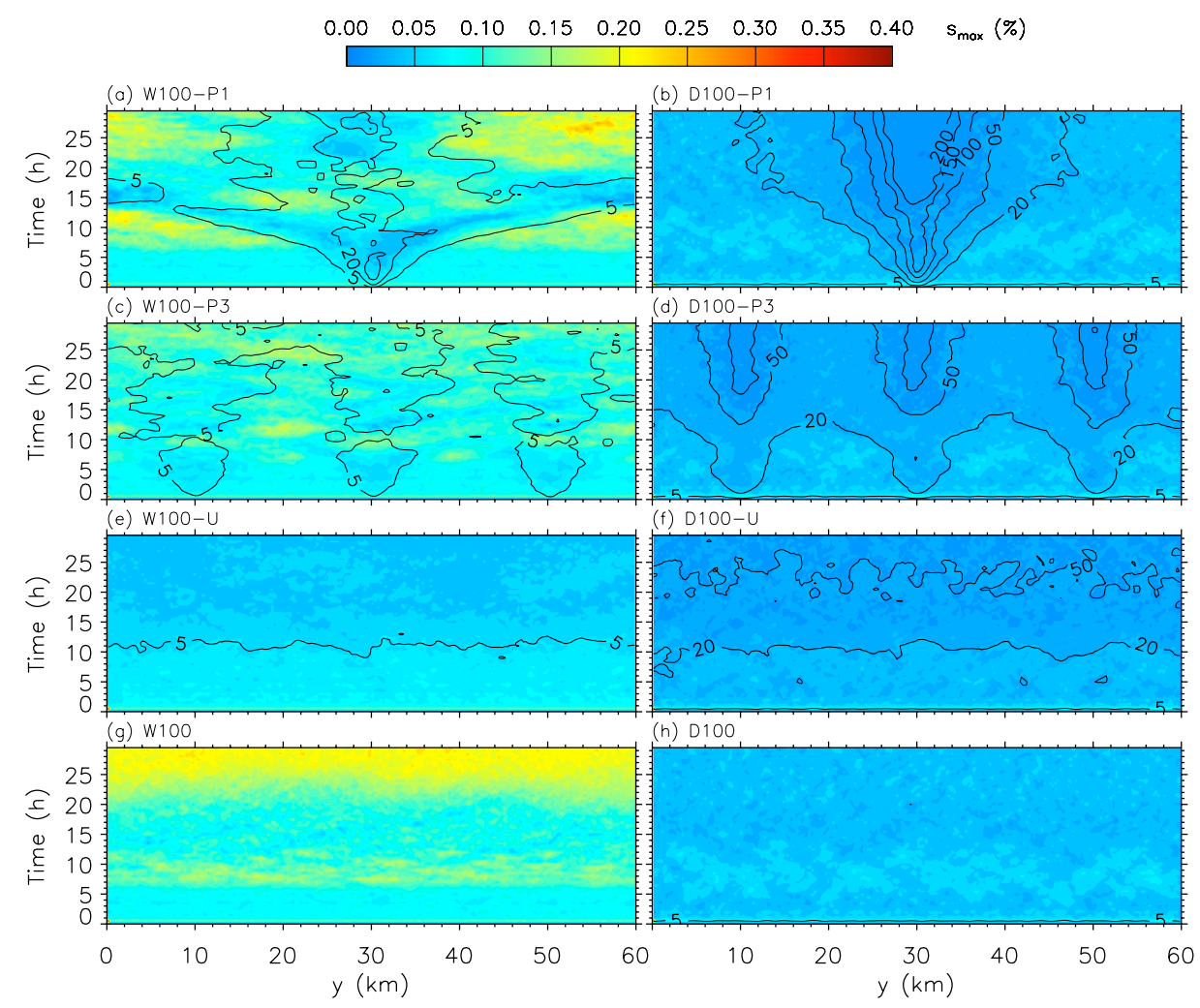

Fig. 4. Same as Fig. 3 but for the W100 and D100 cases.

Table 2. Domain- and time-averaged LWP $\left(\mathrm{g} \mathrm{m}^{-2}\right)$, cloud fraction $\left(f_{\mathrm{c}}, \%\right)$, drop number concentration $\left(N_{\mathrm{d}}, \mathrm{mg}^{-1}\right)$, surface rain rate $\left(R_{\mathrm{r}}, \mathrm{mm} \mathrm{d}^{-1}\right)$, cloud albedo $\alpha_{\mathrm{c}}$ and its change relative to the corresponding baseline simulation. Time-average is taken over the last $24 \mathrm{~h}$ of the simulations.

\begin{tabular}{lrrrrrr}
\hline Experiment & LWP & $f_{\mathrm{c}}$ & $N_{\mathrm{d}}$ & $R_{\mathrm{r}}$ & $\alpha_{\mathrm{c}}$ & $\Delta \alpha_{\mathrm{c}}$ \\
\hline W100 & 64.0 & 41.6 & 11.2 & 1.27 & 0.17 & - \\
W100-P1 & 96.4 & 80.0 & 64.5 & 0.66 & 0.34 & 0.17 \\
W100-P3 & 105.3 & 88.1 & 71.8 & 0.47 & 0.4 & 0.22 \\
W100-U & 133.4 & 99.9 & 153.7 & 0.0 & 0.6 & 0.43 \\
W50 & 56.0 & 32.1 & 6.3 & 1.87 & 0.15 & - \\
W50-P1 & 78.3 & 67.5 & 44.7 & 1.09 & 0.27 & 0.12 \\
W50-P3 & 72.4 & 60.6 & 30.4 & 0.98 & 0.23 & 0.08 \\
W50-U & 66.0 & 53.0 & 17.4 & 0.96 & 0.2 & 0.04 \\
W200 & 131.2 & 99.9 & 168.8 & 0.0 & 0.6 & - \\
W200-P1 & 127.8 & 99.9 & 231.7 & 0.0 & 0.62 & 0.02 \\
W200-P3 & 127.0 & 99.9 & 232.3 & 0.0 & 0.62 & 0.02 \\
W200-U & 126.0 & 99.9 & 234.7 & 0.0 & 0.62 & 0.02 \\
D100 & 22.1 & 50.2 & 54.8 & 0.0 & 0.17 & - \\
D100-P1 & 21.4 & 50.2 & 83.3 & 0.0 & 0.18 & 0.01 \\
D100-P3 & 21.1 & 50.3 & 86.1 & 0.0 & 0.18 & 0.01 \\
D100-U & 20.5 & 49.7 & 86.0 & 0.0 & 0.18 & 0.01 \\
\hline
\end{tabular}

Atmos. Chem. Phys., 11, 4237-4249, 2011 $\alpha_{\mathrm{c}}$ more effective in the $\mathrm{W} 100$ series. The rain rate of weakly precipitating clouds in W100 is very sensitive to changes in $N_{\mathrm{d}}$ (e.g., Wood et al., 2009; also see Fig. 5d). All three injection methods suppress precipitation, but to different extents, and their order of effectiveness is opposite in W100 to that in W50. The uniform-injection method (W100-U) is the most effective one in all cases considered; domain-wide precipitation is completely shut off so that the depletion of $\mathrm{CCN}$ particles through rain that occurs in the baseline simulation is slowed down significantly. $N_{\mathrm{d}}$ remains high enough to prevent precipitation from occurring over the entire $30-\mathrm{h}$ simulation time period. Cloud albedo remains at its initial high value with only small diurnal variation. Cloud properties in W100-U are even comparable to those in the W200 cases (daily averages in Table 2; also in Fig.7). Consistently, the three sprayers (W100-P3) are more efficient than the one sprayer (W100-P1) in reducing precipitation and enhancing $\alpha_{c}$ because more sprayers can spread the same amount of particles to a larger area as seen in Figs. 1 and 2. The prescribed injection rate is strong enough to suppress rain even if the particles are initially evenly distributed in the domain as in $\mathrm{W} 100-\mathrm{U}$, so the overall rain reduction is proportional to the area covered by injected particles. However, this is not the case in the W50 simulations. On the contrary, the most effective method for enhancing $\alpha_{\mathrm{c}}$ is the one-sprayer method (W50-P1), while the uniform injection (W50-U) is the least 


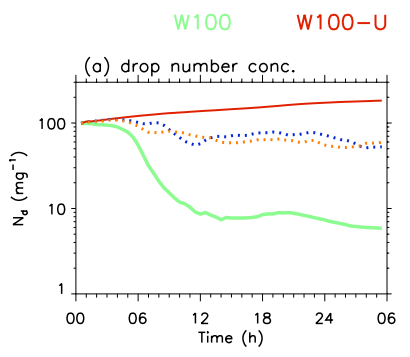

W100-P3 W100-P1
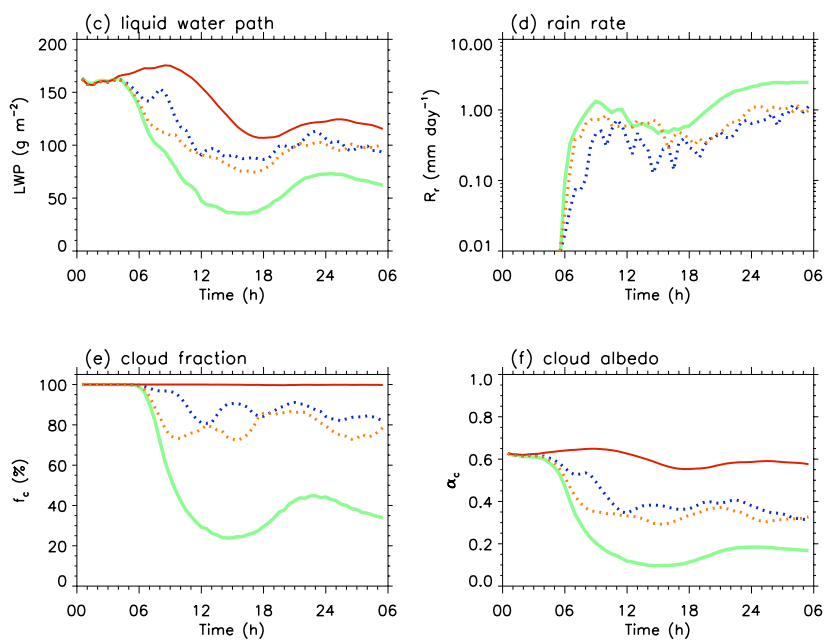

Fig. 5. Time evolution of (a) domain-average drop number concentration $\left(N_{\mathrm{d}}, \mathrm{mg}^{-1}\right)$; (b) cloud-top height; (c) domain-average liquid water path, LWP $\left(\mathrm{g} \mathrm{m}^{-2}\right)$; (d) domain-average surface rain rate $\left(R_{\mathrm{r}}\right.$, $\mathrm{mm} \mathrm{d}^{-1}$ ); (e) cloud fraction; and (f) domain-average cloud albedo $\alpha_{\mathrm{c}}$ for experiments in the W100 series. Cloud fraction is defined as the fractional coverage of the domain by clouds with an optical depth greater than 2 .

effective method (see Fig. 6f). Precipitation is stronger and starts earlier in the cleaner case W50. The open cellular structure is well established before the injected $\mathrm{CCN}$ can have a significant effect. In addition, the depletion of $\mathrm{CCN}$ by rain is a runaway process - a positive feedback between rain production and CCN reduction. $N_{\mathrm{d}}$ is reduced from $50 \mathrm{mg}^{-1}$ to $10 \mathrm{mg}^{-1}$ in the baseline case in less than three hours. The uniform injection in W50-U covers the entire domain but nowhere is it strong enough to boost $N_{\mathrm{d}}$ to significantly weaken the rain production. As a result, the injected particles suffer even stronger depletion than in the point-source cases because of the broader exposure to cloud and rain. Similarly, the three-sprayer case (W50-P3) has lower $N_{\mathrm{d}}$ than the onesprayer case (W50-P1), but is higher than the W50-U case. Consequently, the enhancement of $\alpha_{\mathrm{c}}$ in W50-P3 is between the other two. A more concentrated injection as in W50-P1 is necessary to stop precipitation locally.

Results from the two precipitating cases suggest that for a given amount of seeding material, both areal coverage and local number concentration of injected particles are key players in cloud brightening but neither one emerges as dominant.
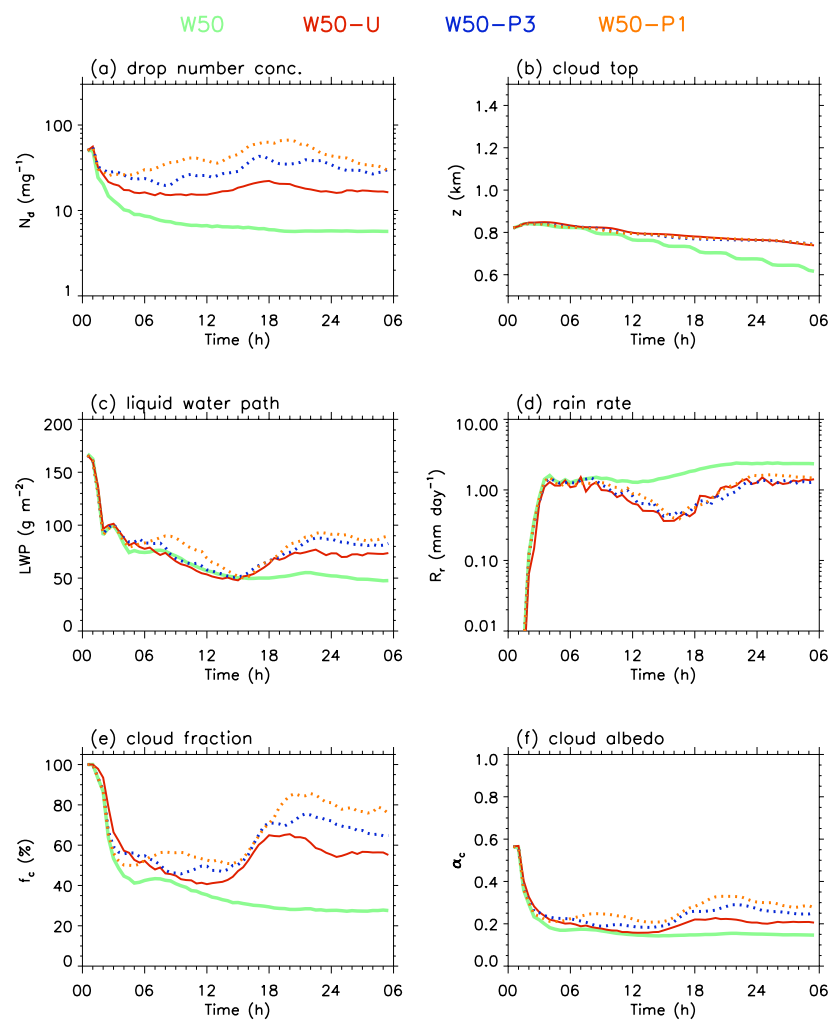

Fig. 6. Same as Fig. 5 but for the W50 series.

The two aspects (areal coverage vs. concentration) need to be balanced to optimize the enhancement of $\alpha_{\mathrm{c}}$. Another point to stress is that retaining cloud water is a more effective way to enhance $\alpha_{\mathrm{c}}$ than just enhancing $N_{\mathrm{d}}$. As seen in the first half of the W50 simulations ( $t<15 \mathrm{~h}$; Fig. 6), CCN injection significantly enhances $N_{\mathrm{d}}$ in W50-U and W50-P3 but is not able to retain LWP. As a result, $\alpha_{c}$ is not enhanced as much as in W50-P1, and in the same case $\alpha_{\mathrm{c}}$ decreases when LWP is reduced significantly.

As the simulations enter the second night (after $t=18 \mathrm{~h}$ ) in the baseline cases W100 and W50, the cloudy boundary layer top drops significantly (Figs. 5b and 6b) due to strong $\mathrm{CCN}$ depletion in the original cloud layer. This is caused by persistent precipitation that also substantially moistens the lower boundary layer. Although $s_{\max }$ is still very high (see Figs. 3 and 4), $N_{\mathrm{d}}$ is extremely low (Figs. 5a and 6a), indicating that the boundary layer is CCN-limited. In this scenario, surface heat and moisture fluxes, as well as particles from the surface, if emitted, are trapped in the decoupled lower-layer, leading to the formation of a thin fog-layer instead of deeper clouds. Injecting particles prior to this change to prevent it from occurring makes the injection more efficient, as we can see that the enhancement of LWP and $\alpha_{\mathrm{c}}$ is more substantial during the second night for the W50 tests compared to the baseline case where the cloud top has become much lower than the capping inversion. 
The results for the precipitating cases also provide some insight into the importance of the timing of seeding. For W100, seeding prior to nighttime thickening of Sc clouds, may be the most effective strategy because it could prevent an overnight shift to open-cellular structure and help sustain solid Sc through the subsequent daylight hours. For W50, early morning seeding to recharge the ultra-clean boundary layer would appear most effective. The most effective timing will clearly be case-dependent, and evaluation of this aspect will be deferred to later study.

Compared to the W50 and W100 cases, cloud brightening in the initially polluted, non-precipitating case W200 and the dry case D100 is much less effective. As shown in Table 2, injection of CCN increases the domain-average $N_{\mathrm{d}}$ but lowers LWP, and more so in the case where injected CCN are more widely distributed in the domain. A decrease in domain-average LWP with almost no change in cloud fraction is likely due to a faster evaporation of smaller droplets (e.g., Wang et al., 2003; Hill et al., 2009) induced by the CCN injection. Similar associations between high aerosol loadings and lower LWP have also been noted by Matsui et al. (2006) based on satellite remote sensing. The same amount of particles added to the W200 domain increases $\alpha_{\mathrm{c}}$ by only 0.02 on average, lower than the target enhancement of 0.06 mentioned by Latham et al. (2008), and it is even lower in the D100 case. Different injection methods do not make a significant difference in these scenarios. Figure 7 shows the time evolution of $N_{\mathrm{d}}$, LWP and $\alpha_{\mathrm{c}}$ for the W200 series. The prescribed particle injection rate steadily increases $N_{\mathrm{d}}$ to about $255 \mathrm{mg}^{-1}$ at the end of the simulation, i.e., $95 \mathrm{mg}^{-1}$ more than the baseline simulation, implying that the clouds have the potential to be further brightened if more $\mathrm{CCN}$ are added and if the LWP can be maintained. Two additional sensitivity simulations, W400 (initial $N_{\mathrm{c}}$ of $400 \mathrm{mg}^{-1}$ ) and W200$\mathrm{P} 3 \times 3$ (tripling the injection rate in $\mathrm{W} 200-\mathrm{P} 3$ ), are performed to see how much more one can enhance $N_{\mathrm{d}}$ and $\alpha_{\mathrm{c}}$ (Fig. 7) if aerosol loadings are further increased. Figure 7 a shows that $N_{\mathrm{d}}$ is much higher in W400 (24-h average, $318 \mathrm{mg}^{-1}$ ) than in W200 but LWP is consistently lower, leading to a small increase in $\alpha_{\mathrm{c}}(0.03$ in the $24 \mathrm{~h})$. Similarly, in W200-P3 $\times 3$ the average $N_{\mathrm{d}}$ over the last $24 \mathrm{~h}$ is boosted to $345 \mathrm{mg}^{-1}$ but LWP is further reduced. As a result, compared to the baseline case W200, $\alpha_{\mathrm{c}}$ is enhanced by $0.04 . N_{\mathrm{d}}$ increases to its maximum $\left(402 \mathrm{mg}^{-1}\right)$ at the end of the simulation, but not the $\alpha_{c}$ because of the simultaneous decrease in LWP. In the dry case (D100), the CCN injection only increases the 24$\mathrm{h}$ average $N_{\mathrm{d}}$ by about $30 \mathrm{mg}^{-1}$. At the end of the simulations when the $\mathrm{CCN}$ number concentration is at its maximum $\left(235-240 \mathrm{mg}^{-1}\right), N_{\mathrm{d}}$ is even smaller than the initial value (80 vs. $95 \mathrm{mg}^{-1}$ ), and $N_{\mathrm{d}}$ no longer increases with the available $\mathrm{CCN}$. A large portion of particles remain unactivated. Further increase in the injection strength is unlikely to make a big difference to $\alpha_{\mathrm{c}}$ because the limitation to cloud albedo enhancement is the small LWP.
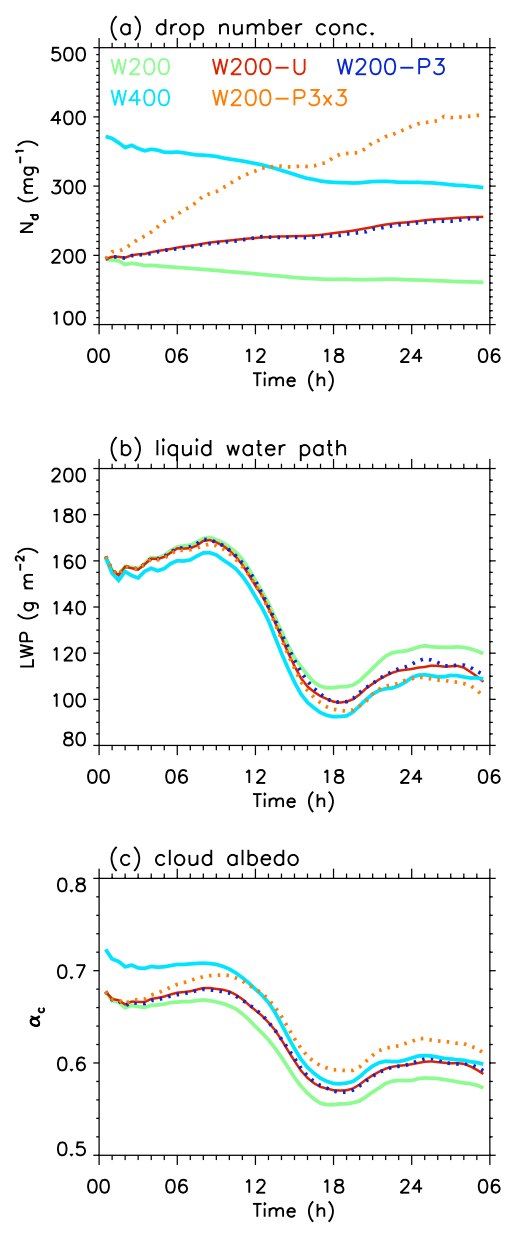

Fig. 7. Time evolution of (a) cloud drop number concentration $\left(N_{\mathrm{d}}\right.$, $\left.\mathrm{mg}^{-1}\right)$, (b) domain-average liquid water path, LWP $\left(\mathrm{g} \mathrm{m}^{-2}\right)$, and (c) domain-average cloud albedo $\alpha_{\mathrm{c}}$ for experiments in the W200 series and two additional ones: W400 (same as W200 but initial $N_{\mathrm{c}}$ is $400 \mathrm{mg}^{-1}$ ) and W200-P3 $\times 3$ (same as W200-P3 but the injection rate is tripled).

\section{Conclusions}

Adding aerosol particles that act as cloud condensation nuclei $(\mathrm{CCN})$ in the marine boundary layer may increase planetary albedo by enhancing the local albedo, spatial coverage and/or longevity of clouds so that more solar energy is reflected back to space. The possibility of mitigating some consequences of climate change by deliberately injecting particles into the marine boundary layer (often called Solar Radiation Management geoengineering or climate engineering methods) was suggested two decades ago (Latham, 1990). These ideas have been explored in a variety of models (see Latham et al., 2011 for a review), but those models did not allow for coupled cloud-aerosol-precipitation interactions and dynamical feedbacks.

In this study, we have used a high-resolution version of the Weather Research and Forecasting (WRF) model with 
explicit treatment of these interactions in a domain approximately the size of a climate model grid box. We run cloudsystem-resolving simulations with four combinations of different meteorological and aerosol background conditions, aimed at improving the process-level understanding of these interactions. Our study is relevant to both fundamental understanding of aerosol-cloud interactions in the presence of aerosol perturbations such as ship tracks as well as to marine cloud geoengineering. In the case of the latter, it provides a necessary and critical test of the method in terms of its effectiveness and efficiency. We investigate how the injected particles are transported within the marine boundary layer and how the additional particles in clouds impact cloud microphysical processes and feedback on dynamics. Single and multiple moving point-sources, as well as a uniform areasource are used to examine the sensitivity of cloud response to $\mathrm{CCN}$ source distribution.

The injection strategy is critical in influencing the spatial distribution of the additional $\mathrm{CCN}$. The injected $\mathrm{CCN}$ are transported vertically into clouds and through the depth of the boundary layer within minutes. The boundary layer eddies do not mix the CCN horizontally very efficiently. Even three sprayers introducing particles into the model domain produce a significant heterogeneous response when the seeding occurs immediately prior to, or during cloud development. The along-track and transverse gradients in CCN number concentration can invoke dynamical feedbacks in precipitating cases that can impact clouds well beyond the traditional "aerosol indirect effects". Some areas become much brighter than others, and local circulations are produced at scales similar to the spatial separation of the sprayers.

Activating additional $\mathrm{CCN}$ to cloud droplets also influences the maximum supersaturation $s_{\max }$ occurring in cloud. It reduces $s_{\max }$ in non-precipitating cases but there are spatial, temporal and case-by-case complexities in the change of $s_{\max }$ in precipitating cases. In addition to the expected reduction in $s_{\max }$ along the injection plumes, $s_{\max }$ can be further reduced by precipitation suppression and attendant reduction in secondary convection associated with outflows. However, precipitation adjacent to the plume may drive a convergent flow that pumps additional moisture into the plume thereby increasing $s_{\max }$ along the injection plumes and reducing $s_{\max }$ on either side. Despite the complexities, the overall domainaverage change is a net decrease in $s_{\max }$ for the cases considered.

Suppressing rain as a means of sustaining cloud water appears to be the most efficient way to enhance cloud albedo in the cases studied here. Results from the precipitating cases suggest that for a given amount of seeding material, both areal coverage and local number concentration of injected particles are key players in cloud brightening but neither one always emerges as dominant. The two aspects (areal coverage vs. concentration) need to be balanced to optimize the enhancement of cloud albedo.
The impact of $\mathrm{CCN}$ injection on cloud properties and therefore, the effectiveness of cloud brightening depends strongly on meteorological conditions, background aerosol and, sometimes, the distribution of sprayers. There are two scenarios under which cloud brightening is very effective. One is a weakly precipitating boundary layer, in which the additional CCN can substantially weaken the precipitation and retain cloud water; here, attaining maximum areal coverage is most effective. The other is a CCN-limited scenario which occurs after heavy and/or persistent precipitation events have depleted $\mathrm{CCN}$ to a level that cloud drops form rain shortly after activation, leaving few $\mathrm{CCN}$ in the original cloud layer. The addition of particles will prevent the boundary layer from collapsing and help sustain clouds. Here high concentration, single sprayer injection is most effective.

Three regimes are found to be less effective or ineffective in cloud brightening:

1. in the strongly precipitating regime, cloud drops grow large enough to rain out efficiently. Adding CCN in the amounts selected here does not suppress the precipitation to an extent that cloud scavenging can be significantly slowed down;

2. in polluted, non-precipitating regimes (with high background $\mathrm{CCN}$ number), clouds are already bright; any further increase in drop number concentration lowers supersaturation and LWP, so that albedo enhancement is negligible;

3. in water-vapor-limited (dry) regimes, LWP is small and turbulence driven by radiative cooling is weak, so incloud supersaturation is very small. Only a very small fraction of added CCN will be activated and any gains in brightening through increases in drop number concentration will be countered by losses in brightening as a result of evaporation-induced decreases in LWP.

The same amount of particles added to the polluted and dry regimes considered in this study increase cloud albedo by only up to 0.02 and different injection methods have little impact. Even tripling the surface injection in the three-sprayer polluted case cannot increase cloud albedo by the desired 0.06 (Latham et al., 2008).

The meteorological conditions simulated here are characteristic of a shallow cloud-topped boundary layer in the Northeast Pacific. The much deeper boundary layer in the Southeast Pacific (e.g., Abel et al., 2010; Bretherton et al., 2010; Wang et al., 2010) will likely respond differently to seeding, and modify some of the conclusions drawn here.

It is also worth noting that with the focus on cloud albedo enhancement we did not consider the direct radiative effect of injected CCN particles, which can be quite significant in the injection plumes. As argued by Latham et al. (2011), there are still many issues related to cloud brightening that need to be investigated and clarified before any implementation can be contemplated. Our study demonstrates that 
a process-level understanding of aerosol-cloud-precipitation interactions is a fundamental precondition. More comprehensive high-resolution modelling assessment and dedicated small-scale field experiments will be of further help in establishing the expected responses of marine stratocumulus clouds in different geographical and meteorological regimes to advertent and inadvertent perturbation by aerosol particles.

Acknowledgements. This research has been funded by the Fund for Innovative Climate and Energy Research (FICER) at the University of Calgary (HW and PJR), and NOAA's Climate Goal program (GF). This does not constitute endorsement of deployment in any form of geoengineering by the funding agencies. We thank John Latham for helpful discussion and comments. Robert Wood and an anonymous referee are thanked for their insightful reviews and valuable comments.

Edited by: R. Krejci

\section{References}

Abel, S. J., Walters, D. N., and Allen, G.: Evaluation of stratocumulus cloud prediction in the Met Office forecast model during VOCALS-REx, Atmos. Chem. Phys., 10, 10541-10559, doi:10.5194/acp-10-10541-2010, 2010.

Ackerman, A. S., Toon, O. B., and Hobbs, P. V.: Dissipation of marine stratiform clouds and collapse of the marine boundary layer due to the depletion of cloud condensation nuclei by clouds, Science, 262, 226-229, 1993.

Ackerman, A. S., VanZanten, M. C., Stevens, B., Savic-Jovic, V., Bretherton, C. S., Chlond, A., Golaz, J.-C., Jiang, H., Khairoutdinov, M., Krueger, S. K., Lewellen, D. C., Lock, A., Moeng, C.-H., Nakamura, K., Petters, M. D., Snider, J. R., Weinbrecht, S., and Zulauf, M.: Large-eddy simulations of a drizzling, stratocumulus-topped marine boundary layer, Mon. Weather Rev., 137, 1083-1110, 2009.

Albrecht, B. A.: Aerosols, cloud microphysics and fractional cloudiness, Science, 245, 1227-1230, 1989.

Bala, G., Caldreia, K., Nemani, R., Cao, L., Ban-Weiss, G., and Shin, H.-J.: Albedo enhancement of marine cloud to counteract global warming: impacts on the hydrological cycle, Clim. Dynam., doi:10.1007/s00382-010-0868-1, 2010.

Bower, K., Choularton, T., Latham, J., Sahraei, J., and Salter, S.: Computational assessment of a proposed technique for global warming mitigation via albedo-enhancement of marine stratocumulus clouds, Atmos. Res., 82, 328-336, 2006.

Bretherton, C. S., Wood, R., George, R. C., Leon, D., Allen, G., and Zheng, X.: Southeast Pacific stratocumulus clouds, precipitation and boundary layer structure sampled along $20^{\circ} \mathrm{S}$ during VOCALS-REx, Atmos. Chem. Phys., 10, 10639-10654, doi:10.5194/acp-10-10639-2010, 2010.

Feingold, G., Walko, R. L., Stevens, B., and Cotton, W. R.: Simulations of marine stratocumulus using a new microphysical parameterization scheme, Atmos. Res., 47-48, 505-528, 1998.

Feingold, G., Cotton, W. R., Kreidenweis, S. M., and Davis, J. T.: Impact of giant cloud condensation nuclei on drizzle formation in marine stratocumulus: Implications for cloud radiative properties, J. Atmos. Sci., 56, 4100-4117, 1999.
Feingold, G., Koren, I., Wang, H., Xue, H., and Brewer, W. A.: Precipitation-generated oscillations in open cellular cloud fields, Nature, 466, 849-852, doi:10.1038/nature09314, 2010.

Hill, A., Feingold, G., and Jiang, H.: The influence of entrainment and mixing assumption on aerosol-cloud interactions in marine stratocumulus, J. Atmos. Sci., 66, 1450-1464, 2009.

Jones, A., Haywood, J., and Boucher, O.: Climate impacts of geoengineering marine stratocumulus clouds, J. Geophys. Res., 114, D10106, doi:10.1029/2008JD011450, 2009.

Korhonen, H., Carslaw, K. S., and Romakkaniemi, S.: Enhancement of marine cloud albedo via controlled sea spray injections: a global model study of the influence of emission rates, microphysics and transport, Atmos. Chem. Phys., 10, 4133-4143, doi:10.5194/acp-10-4133-2010, 2010.

Latham, J.: Control of global warming?, Nature, 347, 339-340, 1990.

Latham, J.: Amelioration of global warming by controlled enhancement of the albedo and longevity of low-level maritime clouds, Atmos. Sci. Lett., 3, 53-58, doi:10.1006/asle.2002.0048, 2002.

Latham, J., Rasch, P., Chen, C.-C., Kettles, L., Gadian, A., Gettelman, A., Morrison, H., Bower, K., and Choularton, T.: Global temperature stabilization via controlled albedo enhancement of low-level maritime clouds, Phil. Trans. Roy. Soc. A, 366, 39693987, 2008.

Latham, J., Bower, K., Choularton, T., Coe, H., Connelly, P., Cooper, G., Craft, T., Foster, J., Gadian, A., Galbraith, L., Iacovides, H., Johnston, D., Launder, B., Leslie, B., Meyer, J., Neukermans, A., Ormond, B., Parkes, B., Rasch, P. J., Rush, J., Salter, S., Stevenson, T., Wang, H., Wang, Q., and Wood, R.: Marine cloud brightening, Phil. Trans. Roy. Soc. A, in review, 2011.

Matsui, T., Masunaga, H., Kreidenweis, S. M., Pielke Sr., R. A., Tao, W.-K., Chin, M., and Kaufman, Y. J.: Satellite-based assessment of marine low cloud variability associated with aerosol, atmospheric stability, and the diurnal cycle, J. Geophys. Res., 111, D17204, doi:10.1029/2005JD006097, 2006.

Randall, D. A., Coakley Jr., J. A., Fairall, C. W., Kropfli, R. A., and Lenschow, D. H.: Outlook for research on subtropical marine stratiform clouds, B. Am. Meteorol. Soc., 65, 1290-1301, 1984.

Rasch, P. J, Latham, J., and Chen, C.-C.: Geoengineering by cloud seeding: influence on sea ice and climate system, Environ. Res. Lett., 4, 045112, doi:10.1088/1748-9326/4/4/045112, 2009.

Russell, L. M., Seinfeld, J. H., Flagan, R. C., Ferek, R. J., Hegg, D. A., Hobbs, P. V., Wobrock, W., Flossmann, A. I., O’Dowd, C. D., Nielsen, K. E., and Durkee, P. A.: Aerosol dynamics in ship tracks, J. Geophys. Res., 104, 31007-31095, 1999.

Salter, S., Sortino, G., and Latham, J.: Sea-going hardware for the cloud albedo method of reversing global warming, Phil. Trans. Roy. Soc. A, 366, 3989-4006, 2008.

Stevens, B. and Feingold, G.: Untangling aerosol effects on clouds and precipitation in a buffered system, Nature, 461, 607-613, 2009.

Stevens, B., Cotton, W. R., Feingold, G., and Moeng, C.H.: Large-eddy simulations of strongly precipitating, shallow, stratocumulus-toped boundary layers, J. Atmos. Sci., 55, 36163638, 1998.

Stevens, B., Moeng, C.-H., Ackerman, A. S., Bretherton, C. S., Chlond, A., de Roode, S., Edwards, J., Golaz, J.-C., Jiang, H., Khairoutdinov, M., Kirkpatrick, M. P., Lewellen, D. C., Lock, A., Muller, F., Stevens, D. E., Whelan, E., and Zhu, P.: Evaluation 
of large-eddy simulations via observations of nocturnal marine stratocumulus, Mon. Weather Rev., 133, 1443-1462, 2005.

Twomey, S.:Influence of pollution on the short-wave albedo of clouds, J. Atmos. Sci., 34, 1149-1152, 1977.

Wang, H. and Feingold, G.: Modeling mesoscale cellular structures and drizzle in marine stratocumulus, Part I: Impact of drizzle on the formation and evolution of open cells, J. Atmos. Sci., 66, 3237-3256, 2009a.

Wang, H. and Feingold, G.: Modeling mesoscale cellular structures and drizzle in marine stratocumulus, Part II: The microphysics and dynamics of the boundary region between open and closed cells, J. Atmos. Sci., 66, 3257-3275, 2009b.

Wang, H., Skamarock, W. C., and Feingold, G.: Evaluation of scalar advection schemes in the Advanced Research WRF model using large-eddy simulations of aerosol-cloud interactions, Mon. Weather Rev., 137, 2547-2558, 2009.
Wang, H., Feingold, G., Wood, R., and Kazil, J.: Modelling microphysical and meteorological controls on precipitation and cloud cellular structures in Southeast Pacific stratocumulus, Atmos. Chem. Phys., 10, 6347-6362, doi:10.5194/acp-10-6347-2010, 2010.

Wang, S. P., Wang, Q., and Feingold, G.: Turbulence, condensation, and liquid water transport in numerically simulated nonprecipitating stratocumulus clouds, J. Atmos. Sci., 60, 262-278, 2003.

Wood, R.: Rate of loss of cloud droplets by coalescence in warm clouds, J. Geophys. Res., 111, D21205, doi:10.1029/2006JD007553, 2006.

Wood, R., Kubar, T., and Hartmann, D. L.: Understanding the importance of microphysics and macrophysics for warm rain in marine low clouds, Part II: Heuristic models of rain formation, J. Atmos. Sci., 66, 2973-2990, 2009. 